\title{
Adaptive divergence, neutral panmixia, and algal symbiont population structure in the temperate coral Astrangia poculata along the Mid-Atlantic United States
}

\author{
Hannah E Aichelman ${ }^{\text {Corresp., 1, } 2 \text {, Daniel J Barshis }}{ }^{2}$ \\ ${ }^{1}$ Department of Biology, Boston University, Boston, Massachusetts, United States \\ 2 Department of Biological Sciences, Old Dominion University, Norfolk, Virginia, United States \\ Corresponding Author: Hannah E Aichelman \\ Email address: haich@bu.edu
}

Astrangia poculata is a temperate scleractinian coral that exists in facultative symbiosis with the dinoflagellate alga Breviolum psygmophilum across a range spanning the Gulf of Mexico to Cape Cod, Massachusetts. Our previous work on metabolic thermal performance of Virginia (VA) and Rhode Island (RI) populations of $A$. poculata revealed physiological signatures of cold (RI) and warm (VA) adaptation of these populations to their respective local thermal environments. Here, we used whole-transcriptome sequencing (mRNA-Seq) to evaluate genetic differences and identify potential loci involved in the adaptive signature of VA and RI populations. Sequencing data from $40 \mathrm{~A}$. poculata individuals, including 10 colonies from each population and symbiotic state (VA-white, VA-brown, RIwhite, and RI-brown), yielded a total of 1,808 host-associated and 59 algal symbiontassociated single nucleotide polymorphisms (SNPs) post filtration. Fst outlier analysis identified 66 putative high outlier SNPs in the coral host and 4 in the algal symbiont. Differentiation of VA and RI populations in the coral host was driven by putatively adaptive loci, not neutral divergence ( $\mathrm{Fst}=0.16, p=0.001$ and $\mathrm{Fst}=0.002, p=0.269$ for outlier and neutral SNPs respectively). In contrast, we found evidence of neutral population differentiation in $B$. psygmophilum ( $F s t=0.093, p=0.001$ ). Several putatively adaptive host loci occur on genes previously associated with the coral stress response. In the symbiont, three of four putatively adaptive loci are associated with photosystem proteins. The opposing pattern of neutral differentiation in B. psygmophilum, but not the A. poculata host, reflects the contrasting dynamics of coral host and algal symbiont population connectivity, dispersal, and gene by environment interactions. 


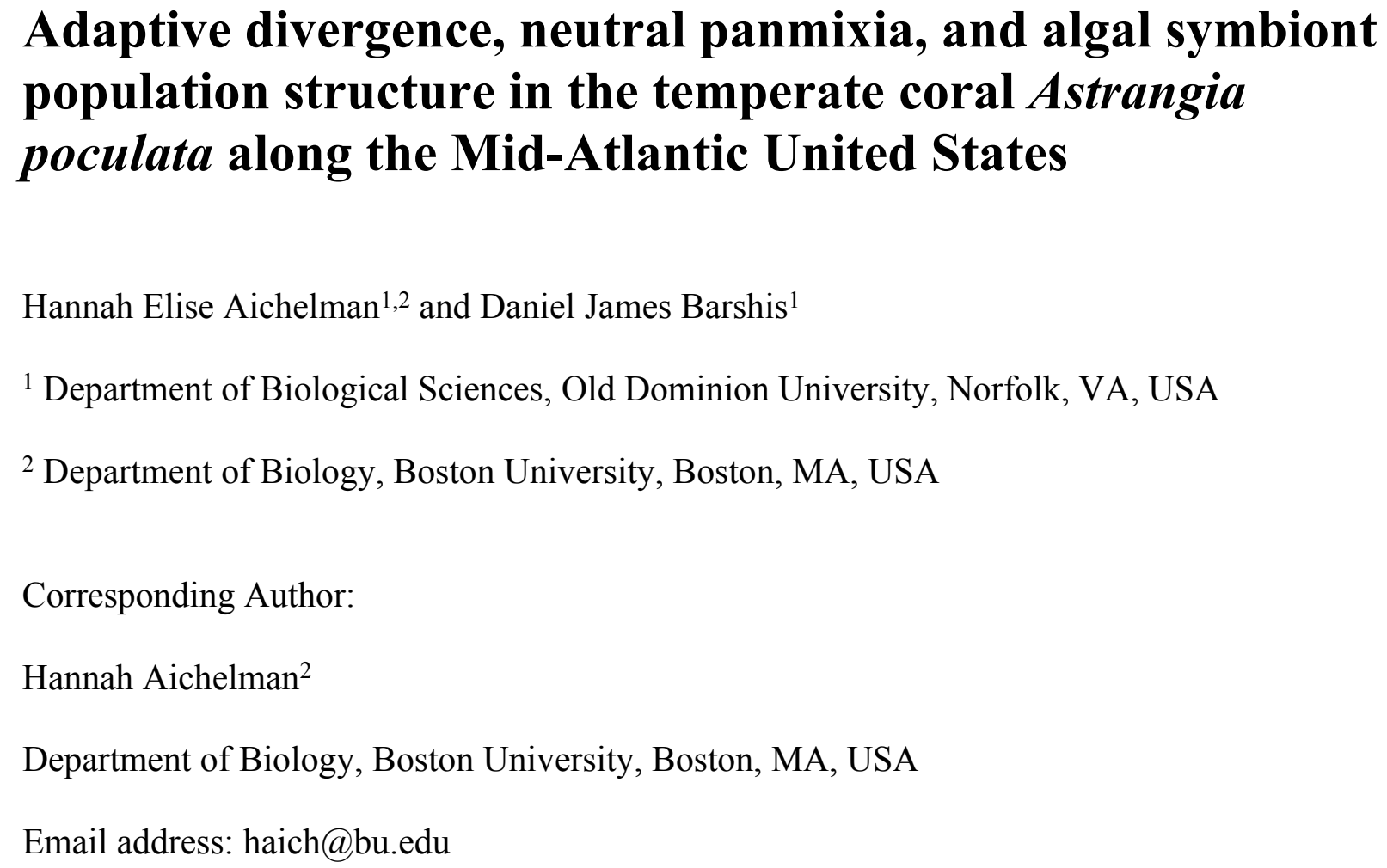




\section{Abstract}

46 Astrangia poculata is a temperate scleractinian coral that exists in facultative symbiosis with the

47 dinoflagellate alga Breviolum psygmophilum across a range spanning the Gulf of Mexico to Cape

48 Cod, Massachusetts. Our previous work on metabolic thermal performance of Virginia (VA) and

49 Rhode Island (RI) populations of $A$. poculata revealed physiological signatures of cold (RI) and

50 warm (VA) adaptation of these populations to their respective local thermal environments. Here,

51 we used whole-transcriptome sequencing (mRNA-Seq) to evaluate genetic differences and

52 identify potential loci involved in the adaptive signature of VA and RI populations. Sequencing

53 data from $40 \mathrm{~A}$. poculata individuals, including 10 colonies from each population and symbiotic

54 state (VA-white, VA-brown, RI-white, and RI-brown), yielded a total of 1,808 host-associated

55 and 59 algal symbiont-associated single nucleotide polymorphisms (SNPs) post filtration. Fst

56 outlier analysis identified 66 putative high outlier SNPs in the coral host and 4 in the algal

57 symbiont. Differentiation of VA and RI populations in the coral host was driven by putatively

58 adaptive loci, not neutral divergence $(F s t=0.16, p=0.001$ and $F s t=0.002, p=0.269$ for outlier and

59 neutral SNPs respectively). In contrast, we found evidence of neutral population differentiation

60 in B. psygmophilum ( $\mathrm{Fst}=0.093, \mathrm{p}=0.001)$. Several putatively adaptive host loci occur on genes

61 previously associated with the coral stress response. In the symbiont, three of four putatively

62 adaptive loci are associated with photosystem proteins. The opposing pattern of neutral

63 differentiation in B. psygmophilum, but not the $A$. poculata host, reflects the contrasting

64 dynamics of coral host and algal symbiont population connectivity, dispersal, and gene by

65 environment interactions.

66

67 
68

69

70

71

72

73

74

75

76

77

78

79

80

81

82

83

84

85

86

87

88

89

90

\section{Introduction}

Population connectivity in marine systems is shaped by a complex mixture of factors, including oceanographic currents (Selkoe et al. 2008), planktonic larval durations and behavior (Selkoe \& Toonen 2011), life history dynamics (Bradbury et al. 2008), and environmentally driven selection (Limborg et al. 2012), among others (reviewed in Selkoe \& Toonen 2011). The result of these interacting forces can manifest in numerous ways, including wide-ranging panmixia across 1000 s of kilometers (e.g. Dao et al. 2015), extraordinarily fine-scaled neutral population structure across 10s of meters (e.g. Aurelle et al. 2011; Costantini et al. 2007; Ledoux et al. 2010), or local adaptation over both small and large spatial scales (e.g. Bay \& Palumbi 2014; Bradbury et al. 2010). Patterns of population connectivity in marine systems are made only more complex when considering organisms as multi-organism symbiotic communities, or holobionts, and each member of the holobiont can be subject to opposing forces driving population structure.

1 In scleractinian corals, the holobiont consists of the coral host, algal symbiont (family Symbiodiniaceae; LaJeunesse et al. 2018), and associated microbiota (Knowlton \& Rohwer 2003; Rohwer et al. 2002). While patterns are often complicated by species and location, population structure of the coral host is generally affected by reproductive strategy, with broad scale dispersal usually more common in broadcast spawning species compared to brooding species (Ayre \& Hughes 2000; Coelho \& Lasker 2016). Patterns of differential connectivity of coral hosts and symbionts has also been observed, with coral hosts generally exhibiting connectivity across larger scales compared to their hosted algal symbionts (Baums et al. 2014;

Pettay \& LaJeunesse 2013; Pinzon \& LaJeunesse 2011). This difference in dispersal among symbiotic partners could be influenced by distinct life history strategies and resulting dispersal 
91 abilities, transmission strategy of symbionts (i.e. horizontal vs. vertical), and/or differential

92 selection pressures (Baums et al. 2014).

Temperature is one environmental factor that can impose strong selection pressure on natural populations and therefore drive population differentiation (Angilletta 2009), and is a common focus in the coral literature. Temperature gradients as drivers of selection and local adaptation have been demonstrated in corals, including Porites astreoides across nearshore and

97 forereef environments on the Florida Keys Reef Tract (Kenkel et al. 2013; Kenkel \& Matz 2016) and $P$. lobata inhabiting tidal pools in American Samoa with differing patterns of thermal variability (Barshis et al. 2018; Barshis et al. 2010). While we are only beginning to understand these dynamics in tropical corals, comparatively little is known about the forces that shape population structure in temperate scleractinian corals, which exist across vastly wider environmental gradients. However, work in Oculina spp. has demonstrated genetic differentiation of the host did not correlate with Symbiodiniaceae community composition; instead, symbiont diversity and geographical structuring was shaped most strongly by sea surface temperature, particularly within the Mediterranean (Leydet \& Hellberg 2016). Additionally, work on temperate octocorals in the Mediterranean has demonstrated local adaptation to distinct temperature regimes across depths (Haguenauer et al. 2013; Ledoux et al. 2015) while highlighting genetic drift in limiting such phenotypic differentiation (Crisci et al. 2017; Ledoux et al. 2015). coral, Astrangia poculata (=A. danae; Peters et al., 1988), and its algal symbiont Breviolum

112 psygmophilum (LaJeunesse et al. 2012). Astrangia poculata is facultatively symbiotic, meaning 113 it can exist both with (symbiotic or brown) or without (aposymbiotic or white) B. psygmophilum 
114 across its range (Boschma 1925). Therefore, the forces shaping host population structure may be

115 decoupled from those shaping the algal symbiont. Our previous work (Aichelman et al. 2019)

116 demonstrated physiological differentiation between a Virginia (VA) and Rhode Island (RI)

117 population of $A$. poculata. Namely, the thermal optimum $\left(\mathrm{T}_{\mathrm{opt}}\right)$ of respiration was elevated in VA

118 corals compared to $\mathrm{RI}\left(3.8^{\circ} \mathrm{C}\right.$ and $6.9^{\circ} \mathrm{C}$ greater in brown and white corals, respectively),

119 corresponding with warmer in situ temperatures in the more southern population and suggestive

120 of a signature of adaptation of VA and RI corals to their native thermal habitat.

121 Studies from Narragansett Bay, RI have demonstrated that $A$. poculata is a gonochoristic

122 broadcast spawner that releases its gametes into the water column between early August and

123 September (Szmant-Froelich 1980). A. poculata horizontally transmits its symbionts, and recruits

124 therefore acquire symbionts locally once they have settled in their new environment (Szmant-

125 Froelich 1980). Original studies on $A$. poculata life history observed the development of the

126 planula larval stage 12 to 15 hours after fertilization, but researchers were unable to induce

127 settlement (Szmant-Froelich 1980). Achieving larval settlement in the lab remains challenging in

128 this species today; however, larvae have been observed to remain swimming for at least 5 weeks

129 in the lab (D. Wuitchik, personal communication), suggesting an extended pelagic larval 130 duration (PLD).

131 In the current study, we characterized population structure of the $A$. poculata host and its

132 symbiont (B. psygmophilum) both by population (VA vs. RI) and by symbiotic state (brown vs.

133 white) using SNPs derived from high-throughput mRNA-Seq data. Leveraging our previous

134 work on physiological adaptation in these populations, we explore the relative strengths of

135 neutral and adaptive divergence in this broadcast spawning, facultatively symbiotic, and

136 extraordinarily thermally resilient species across the northern half of its range. 


\section{2. Materials \& Methods}

\section{$138 \quad 2.1$ Sample collection}

Corals were collected from the same sites and using the same methods as previously

140 described (Aichelman et al. 2019). Here, in August and September, 2017, brown and white

141 Astrangia poculata colonies were collected each from Virginia (VA) and Rhode Island (RI),

142 USA (populations will be referred to as VA-brown $[\mathrm{n}=10]$, VA-white $[\mathrm{n}=10]$, RI-brown $[\mathrm{n}=$

143 10], and RI-white $[\mathrm{n}=10])$. All brown and white VA colonies were collected from the wreck of

144 the J.B. Eskridge (36'53'57.1'N, 7543'20.6”'W) on September 15, 2017 at $20 \mathrm{~m}$ depth (Figure

145 1). All VA colonies were transported to the Old Dominion University (ODU) Aquatics Facility

146 within 6 hours of collection. All brown and white RI colonies were collected from Fort Wetherill

147 State Park (41²8'38.7’N, 71²1'36.3”W) on August 3, 2017 from a depth of $11 \mathrm{~m}$ (Figure 1).

148 RI colonies were maintained overnight submerged in Narragansett Bay and then transported by

149 car in an aerated aquarium to ODU the next day. All VA and RI colonies were collected using a

150 hammer and chisel and were separated by at least $0.5 \mathrm{~m}$ to ensure the collection of distinct

151 individuals. VA corals were collected under Virginia Marine Resources Commission permit \#17-

152 017, while no permit was required for collection of RI corals.

Following both collections, all $\mathrm{A}$. poculata colonies were placed in a holding aquarium at

$154 \mathrm{ODU}$ and maintained at a temperature of $18^{\circ} \mathrm{C}\left( \pm 0.5^{\circ} \mathrm{C}\right)$ and salinity of approximately $35 \mathrm{ppt}$

155 for a recovery period before fragmentation (5 days for VA corals, 48 days for RI corals). Corals

156 were fragmented over two days (September 20 - 21, 2017) using a high-speed cut off tool

157 (Chicago Pneumatic, Rock Hill, SC, USA) fitted with a diamond tip circular blade (sensu

158 Aichelman et al. 2019), then affixed to labeled underwater paper using InstaCure ethyl

159 cyanoacrylate gel (IC-Gel; Bob Smith Industries Inc., Atascadero, CA, USA). All individuals 
160 (i.e. putative genets) were fragmented into three pieces, so that a ramet from each genet was

161 represented in each of the three temperature treatments $\left(\operatorname{cold}=14^{\circ} \mathrm{C}\right.$, control $=18^{\circ} \mathrm{C}$, and heat $=$

$16222^{\circ} \mathrm{C}$ ). Following fragmentation, all corals were allowed to recover at the holding conditions

$163\left(18^{\circ} \mathrm{C}\right.$ and $\left.35 \mathrm{ppt}\right)$ for 20 days before the experiment began. While this experiment was designed

164 to consider differential gene expression in A. poculata across temperatures and populations; here,

165 we present sequencing data from this same experiment and resulting single nucleotide

166 polymorphisms (SNPs) to consider population structure.

\section{$167 \quad 2.2$ Temperature environment of coral populations}

168 To compare long-term temperature trends across the two collection sites, sea surface

169 temperature (SST) data was downloaded from the NOAA 1/4 daily Optimum Interpolation Sea

170 Surface Temperature dataset (OISST, dataset ID=ncdcOisst2Agg_LonPM180; Banzon et al.

171 2020) using the griddap function implemented in R (v3.5.2). Data was downloaded for the years

1721982 to 2018 spanning the area 30 to $45^{\circ}$ latitude and -80 to $-60^{\circ}$ longitude. Annual maximum

173 temperature (Figure 1), annual mean (Figure S1A), and annual minimum temperature (Figure

174 S1B) of each $1 / 4^{\circ}$ pixel were calculated from this dataset. The OISST temperature data were

175 downloaded, compiled, and plotted with a high-resolution shoreline map layer (Wessel \& Smith

176 1996) using the method detailed in the GitHub repository associated with this publication.

\section{$177 \quad 2.3$ Aquaria conditions}

178 Similar to Aichelman et al. (2019), following collection all experimental corals were

179 maintained in a 325-gallon holding aquarium with artificial seawater mixed using Crystal Sea ${ }^{\circledR}$

180 Bioassay salt (Marine Enterprises International, Baltimore, MD, USA) and deionized (DI) water.

181 Temperature was maintained using a temperature controller (AquaLogic, San Diego, CA, USA)

182 in combination with an in-line water chiller (Delta Star ${ }^{\circledR}$, AquaLogic, San Diego, CA, USA) and 
$1831500 \mathrm{~W}$ immersion heater (Process Technology, Willoughby, Ohio, USA). The holding

184 aquarium was equipped with a filter sock for mechanical filtration, protein skimmer for removal

185 of organic material, and powerheads (Tunze ${ }^{\circledR}$ Turbelle, Penzburg, Germany) to maintain flow.

186 All experimental corals were fed three times a week with freshly hatched Artemia sp. nauplii and

187 maintained under approximately $200 \mu \mathrm{mol}$ photons $\mathrm{m}^{-2} \mathrm{~s}^{-1}$ of light supplied by $165 \mathrm{~W}$ LED

188 aquarium lights (GalaxyHydro, Roleadro, Shenzhen, China).

189 The experiment was run in three separate aquaria, one for each temperature treatment

$190\left(\right.$ cold $=14^{\circ} \mathrm{C}$, control $=18^{\circ} \mathrm{C}$, and heat $\left.=24^{\circ} \mathrm{C}\right)$. As in the holding aquarium, artificial seawater

191 was mixed to $35 \mathrm{ppt}$ and each aquarium was equipped with a filter sock and protein skimmer. In

192 the heat and cold aquaria, temperature was manipulated using a custom-programmed Arduino ${ }^{\circledR}$

193 (code assembled by D. Barshis) connected to the same style heater and chiller as the holding

194 aquarium (sensu Aichelman et al. 2019). Temperature in the control experimental aquarium was

195 maintained using a temperature controller as in the holding aquarium (AquaLogic, San Diego,

196 CA, USA).

\section{$197 \quad 2.4$ Experimental design}

198 At 08:00 on October 12, 2017, all corals were moved from the holding tank to one of the

199 three experimental aquaria, such that each genotype was represented in each temperature

200 treatment. Each experimental aquarium was maintained at conditions identical to the holding

201 tank ( salinity $=35 \mathrm{ppt}$, temperature $\left.=18^{\circ} \mathrm{C}\right)$. All corals were given 30 minutes of acclimation in

202 the dark, after which the lights were turned on and a one hour hold at $18^{\circ} \mathrm{C}$ began. At 09:30,

203 temperature was increased (heat aquarium) and decreased (cold aquarium) at a rate of $4^{\circ} \mathrm{C} \mathrm{hr}{ }^{-1}$,

204 and the target temperatures of $22^{\circ} \mathrm{C}$ (heat) and $14^{\circ} \mathrm{C}$ (cold) were reached at 10:30. The corals 
205 were held at their respective target temperatures for another hour, and the experiment therefore 206 ended at 11:30 (Figure S2).

207 Immediately upon completion of the experiment, tissue samples of approximately $1 \mathrm{~cm}^{2}$ 208 were taken from each coral fragment and preserved in an RNAlater-like solution (De Wit et al. 209 2012). RNA sampling took place between 11:30 and 13:10, and all fragments were maintained at 210 their respective experimental condition until sampling occurred. The tissue samples were stored 211 in RNALater at $-80^{\circ} \mathrm{C}$ until RNA extraction.

212 Temperature was monitored throughout the experiment using Hobo Pendant ${ }^{\circledR}$

213 Temperature Data Loggers (Onset Computer Corporation, Bourne, MA, USA; Figure S2), which

214 recorded water temperature at one-minute intervals. Temperature loggers were calibrated with a 215 NIST certified glass thermometer. Light levels in each experimental aquarium were maintained 216 at $410 \mu \mathrm{mol}$ photons $\mathrm{m}^{-2} \mathrm{~s}^{-1}$ during the experiment, as measured in the center of each aquaria and 217 supplied by a 165 W LED aquarium light (GalaxyHydro, Roleadro, Shenzhen, China). The light

218 levels used here were based on an estimation of minimum saturating irradiance from our 219 previously published photosynthesis vs. irradiance curve (Aichelman et al. 2019) as well as 220 previous work by Jacques (1983).

\section{$221 \quad 2.5$ Library preparation and sequencing}

RNA was extracted from all coral fragments between November 1 and 13, 2017 using

223 Trizol (Invitrogen, Carlsbad, CA, USA). For each extraction, coral tissue samples were thawed,

224 crushed with a sterile razor blade, combined with Trizol and sterile $0.5 \mathrm{~mm}$ zirconia/silica beads

225 (BioSpec Products, Bartlesville, OK, USA) and bead beat on high for 2 minutes to break open

226 cells. Following a 5-minute incubation at room temperature, samples were centrifuged for 10

227 minutes at $12,000 \mathrm{x}$ g and $4^{\circ} \mathrm{C}$ to pellet the skeleton and beads. The supernatant was combined 
228 with $200 \mu \mathrm{l}$ of chloroform and mixed for 15 seconds. Following another 5 -minute incubation,

229 samples were spun for 15 minutes at $12,000 \times$ g and $4^{\circ} \mathrm{C}$, and the chloroform cleaning step was

230 repeated. After the last centrifugation step, the supernatant was combined with an equal volume

231 of $95 \%$ ethanol and all samples were immediately purified using a Direct-zol RNA MiniPrep

232 Plus purification kit (Zymo Research, Irvine, CA, USA) according to manufacturer's

233 instructions. The purified RNA was eluted in $50 \mu \mathrm{L}$ of DNase/RNase-free water and

234 immediately stored at $-80^{\circ} \mathrm{C}$ for future library preparation. The concentration of all RNA

235 extractions was assessed using a Qubit 2.0 Fluorometer (Invitrogen by Life Technologies) and

236 diluted to $0.1-1 \mu \mathrm{g}$ total RNA before mRNA-Seq library preparation.

237 Libraries $(\mathrm{N}=96)$ were prepped using the Illumina TruSeq mRNA prep kit (San Diego,

238 CA, USA) and half-sized reaction volumes. The 96 libraries consisted of 7 genotypes per

239 population (RI-brown, RI-white, VA-brown, VA-white), with each genotype represented across

240 all temperature treatments $(7$ genotypes $\times 4$ populations $\times 3$ temperature treatments $=84$

241 libraries). These 84 libraries were intended for use in differential gene expression analysis. An

242 additional 12 libraries, intended to increase the sample size for SNP analyses, were prepared

243 from 3 additional genotypes per population ( 3 genotypes $x 4$ populations $=12$ libraries), all of

244 which were in the $18^{\circ} \mathrm{C}$ control treatment.

245 The quality and quantity of all mRNA-Seq libraries was assessed using both a fragment

246 analyzer (DNF-910 dsDNA Reagent Kit, Advanced Analytical) and KAPA Library

247 Quantification Kit for Illumina platforms (Roche Sequencing Solutions, Pleasanton, CA, USA).

248 Any libraries that did not successfully amplify after the first attempt were prepped again using

249 the same method listed above, except $25 \mu \mathrm{L}$ of un-diluted RNA was used in the Illumina TruSeq

250 mRNA prep kit. The 96 libraries were sequenced on 6 lanes of an Illumina HiSeq4000 (16 
251 libraries per lane) at the University of California Berkeley Vincent J. Coates Genomics

252 Sequencing Laboratory, which yielded single-end 50 base pair (bp) reads. All RNA sequences

253 have been deposited in NCBI BioProject under accession number PRJNA614998.

$254 \quad 2.6$ Processing sequences and transcriptome assembly

255 Detailed descriptions for all data analyses can be found on the electronic notebook

256 associated with this publication (github.com/hannahaichelman/Astrangia_PopGen). Raw

257 sequences were processed using the adapter trimming/quality filtering functions of the Fastx-

258 Toolkit to remove adapter sequence contamination and reads with a quality score less than 33 .

259 All sequences were then used as input for de novo transcriptome assembly using Trinity (version

260 2.0.6; Grabherr et al. 2011) and default parameters. Ribosomal RNA (rRNA) contamination of

261 the reference was identified using nucleotide blast (blastn) against the Silva large subunit (LSU)

262 and small subunit (SSU) databases (http://www.arb-silva.de/). "Good hits" to these rRNA

263 databases were defined as matching at least $78 \%$ of the read over at least $100 \mathrm{bp}$, and once

264 identified were removed from the reference assembly. A total of 1,273 matches to the LSU

265 database and 688 matches to the SSU database were removed from the reference assembly.

266 Once rRNA contamination was removed from the reference assembly, it was filtered to

267 include only sequences greater than 500 bp in length. Host and symbiont contigs in the reference

268 assembly were differentiated and assigned as described previously (Barshis et al. 2013; Davies et

269 al. 2016; Ladner \& Palumbi 2012). Briefly, the reference assembly was blasted (using blastn)

270 against four databases: 1) all available cnidarian data (“dirty coral”; $\mathrm{n}=10$ datasets), 2) all

271 available Symbiodiniaceae data (“dirty sym"; $n=8$ datasets), 3) aposymbiotic cnidarian data

272 only ("clean coral"; $\mathrm{n}=15$ datasets), and 4) cultured Symbiodiniaceae data only ("clean sym"; $\mathrm{n}$

$273=9$ datasets). These four databases contained the same sequencing data used by Davies et al. 
274 (2016), plus an additional 16 datasets (summarized in Table S1). A contig was considered a host

275 contig if it had a length overlap greater than $100 \mathrm{bp}$ with a $60 \%$ identity cutoff to any cnidarian.

276 If the same contig was also assigned to a cultured (clean) symbiont read with the same length

277 and cutoff identity, it was removed from the host contig list. Similarly, a contig was considered a

278 symbiont contig if it had a length overlap greater than $100 \mathrm{bp}$ with a $60 \%$ identity cutoff to any

279 symbiont, and removed if it also assigned to a clean coral reference. Contigs identified as both

280 coral and symbiont were also removed from the reference.

281 Once contigs were designated as host or symbiont, the resulting Trinity-assembled

282 reference was annotated by BLAST sequence homology searches against GenBank's nr protein

283 database (Coordinators 2018) and UniProt's Swiss-Prot and TrEMBL databases (Consortium

284 2018) to create a consensus annotation using an $e$-value cutoff of $1 \mathrm{e}^{-4}$ using a custom annotation

285 script (De Wit et al. 2012). Annotated sequences were then assigned to Gene Ontology (GO)

286 categories (Consortium 2018). Reference transcriptome size and contiguity was assessed using a

287 custom python script (Table 1).

$288 \quad$ 2.7 SNP calling and clone identification

289 To maximize the total reads per genotype for the population genetic analyses presented

290 here, fastq files were combined by genotype. This reduced 84 libraries ( 7 genotypes x 4

291 populations $\times 3$ temperature treatments) to 28 fastq files. These concatenated files, along with the

29212 libraries originally intended for population genetic analyses, yielded a total of 40 libraries that

293 were used for all downstream analyses. It should be noted that the dataset presented here had

294 relatively low read counts, resulting from an error in the library preparation that led to

295 sequencing of rRNA in addition to mRNA. The primary result of this error was a larger than

296 usual percentage of sequence yield going to rRNA, which resulted in a lower read count on an 
297 individual basis. To combat this, we have used conservative cut-off values at every step of the 298 data analysis pipeline to address these issues and account for missing data.

The quality filtered reads were mapped to the de novo holobiont transcriptome using the "very-sensitive" method of Bowtie2.2.4 (Langmead \& Salzberg 2012). Single nucleotide polymorphisms (SNPs) were detected from the mapped reads using freebayes (Garrison \& Marth 2012). The resulting unfiltered variant call file (vcf) was separated into "good coral SNPs" and "good symbiont SNPs" using the lists of coral and symbiont contigs in the reference transcriptome. These coral and symbiont vcf files were then separately filtered using vcftools (v0.1.12b) and utilizing scripts from the dDocent/2.24 pipeline (Puritz et al. 2014a; Puritz et al. 2014b) to create a rigorously filtered set of variant sites. The filtering parameters were the same for the host and symbiont SNPs, and each file was filtered in four steps. First, vcftools was used to filter files to exclude individuals with more than $50 \%$ missing data, exclude sites with minor allele count (mac) greater than or equal to 3 , only include sites with a quality score above 30 , exclude genotypes with fewer than 5 reads, include only bi-allelic sites, and remove indels.

311 Second, the filter_missing_ind.sh script from dDocent was used to remove individuals with more 312 than $85 \%$ missing data. Third, another round of vcftools filtering was conducted to exclude sites 313 if they had more than $75 \%$ missing data, include sites with a minor allele frequency (maf) greater 314 than or equal to 0.05 , and include sites with mean depth values (across all included individuals) 315 greater than or equal to 10. After these filters were executed, the fourth filtering step used the 316 filter_hwe_by_pop.pl script from dDocent to remove sites out of Hardy-Weinberg equilibrium 317 within each population (minimum Hardy-Weinberg p-value cutoff for SNPs $=0.01$ ). This fourth 318 filter resulted in no SNPs being removed from the symbiont file, but 11 SNPs being removed 319 from the coral file. The filtered vcf files were converted to genepop format using a custom 
320 python script (written by D. Barshis). The coral host analysis was conducted considering the data

321 as four populations (VA-B, VA-W, RI-B, and RI-W). The symbiont data only included brown

322 hosts and was therefore analyzed as two populations (VA-B and RI-B). Additionally, to look for

323 consistent loci driving patterns of differentiation between brown and white phenotypes within

324 VA and RI, the coral host analysis was also conducted as two populations for each origin

325 separately (VA-B and VA-W separately from RI-B and RI-W).

326 Potential clones in the coral host data were assessed using the R package poppr (v2.8.5)

327 (Kamvar et al. 2015; Kamvar et al. 2014). The filtered vef file was imported into R and

328 converted into the genind format. Then, the diss.dist function was used to calculate a distance

329 matrix based on relative dissimilarity (i.e. Hamming's distance; Hamming 1950; Wang et al.

330 2015), or the number of allelic differences between two individuals. The distance matrix was

331 clustered with hclust and a dendrogram was plotted to identify clones. Two RI-B individuals

332 were determined to be clones using this method, and one was randomly removed for all

333 downstream analyses (Figure S3). To ensure that the clone identification was robust to other

334 measures of genetic distance, this method was repeated with Prevosti distance (Prevosti et al.

335 1975) and Manhattan distance (using the vegdist function in the package vegan v2.4-2; Oksanen

336 et al. 2011), and the same pair of clones was detected each time.

$337 \quad 2.8$ Outlier detection

338 Neutral and outlier SNPs were detected using BayPass3.04 (Gautier 2015) under the core

339 model. Outlier SNPs under the core model were determined based on the XtX statistic

340 (introduced by Günther \& Coop 2013), which is a SNP-specific Fst corrected for the scaled

341 covariance of population allele frequencies (Gautier 2015). Outlier SNPs were defined as having

$342 \mathrm{XtX}>0.5 \%$ FDR from a simulated dataset. The results of the BayPass analysis were used to 
343 create a neutral and a high outlier list of SNPs, and these two sets were analyzed separately for

344 all downstream analyses. Total numbers of neutral and outlier SNPs are summarized in Table 2.

$345 \quad 2.9$ Population structure and genetic diversity analyses

346 Following BayPass outlier detection, the coral and symbiont vcf files were each filtered

347 to create separate files for neutral and high outlier SNPs. These separate vcf files were then

348 randomly filtered to include only one SNP per contig using the

349 Filter_one_random_snp_per_contig.sh script from the dDocent pipeline (Puritz et al. 2014a;

350 Puritz et al. 2014b). This was done to avoid potential bias of analyses due to non-independence

351 of SNPs on the same contig. All analyses besides BayPass outlier detection used files that were

352 first separated by neutral and outlier SNPs and then filtered to include only one SNP per contig.

353 Pairwise differentiation (Fst) calculations were conducted in GenoDive v3.04 (Meirmans

$354 \&$ Van Tienderen 2004) using the AMOVA Fs method and tested with 999 permutations.

355 AMOVA analyses were conducted in GenoDive using the infinite allele model (Fs-analog), a

356 structure of allele nested within individual nested within population, and tested with 999

357 permutations. Measures of genetic diversity per population, including observed heterozygosity

358 (Ho) and heterozygosity within subpopulations (i.e. expected heterozygosity; Hs) were

359 calculated in GenoDive using default settings. To visualize population differentiation, Principal

360 Component Analysis (PCA) was conducted using the R (v3.5.2) package Adegenet (R Core

361 Team 2017).

STRUCTURE (v2.6), with a 100,000 burn-in period and 500,000 MCMC runs after burn-

363 in, was used to determine the number of distinct genetic groups in the coral host (Falush et al.

364 2007). The optimal number of genetic clusters (K) was assessed using the DeltaK method 
365 (Evanno et al. 2005), which was computed via the online program StructureSelector (Li \& Liu

366 2018) and plotted (Figure S4) using the online program Clumpak (Kopelman et al. 2015).

367

368

369

370

371

372

373

374

375

376

377

378

379

380

381

382

383

384

385

386

387

\subsection{Gene Ontology (GO) enrichment of outlier SNPs}

A gene ontology (GO) Enrichment Analysis was conducted to determine if genes containing outlier SNPs were enriched for any particular GO categories. Each gene in the reference transcriptome received a binary indicator of whether it contained an outlier SNP or not, and a GO enrichment analysis based on Fisher's exact test was used to determine if these outlier SNPs were enriched for any GO categories. Results were plotted as a dendrogram (Figure S5), which indicates gene sharing between GO categories and lists the number of genes in the module over the total number of genes assigned to each category in the entire SNP dataset (e.g. Davies et al. 2016; Dixon et al. 2015).

\section{Results}

\subsection{Mapping and SNP numbers}

The total counts of $A$. poculata mapped reads/genet ranged from 9,340,966 to $167,484,549$, and mapping efficiencies ranged from $45.96 \%$ to $54.10 \%$ (Table 3 ). The unfiltered vcf file had a total of 1,214,003 variants, 432,676 of which were on host contigs and 16,417 of which were on symbiont contigs. After all filters were applied, there were a total of 1,808 coral SNPs, and 59 symbiont SNPs (2 populations including brown individuals only; Table 2). After removing individuals with a high percentage of missing data from the coral vcf file ( $\mathrm{n}=2 \mathrm{RI}-\mathrm{B}$, $\mathrm{n}=2 \mathrm{RI}-\mathrm{W}, \mathrm{n}=1$ VA-B) as well as removing one putative clone (RI-B), a total of 34 individuals remained in the coral analysis ( $n=7$ RI-B, $n=8$ RI-W, $n=9$ VA-B, $n=10$ VA-W). For the symbiont analysis, two individuals with a high percentage of missing data $(\mathrm{n}=2$ VA-B) were 
388 removed, leaving 38 individuals in the symbiont analysis $(\mathrm{n}=10 \mathrm{RI}-\mathrm{B}, \mathrm{n}=10 \mathrm{RI}-\mathrm{W}, \mathrm{n}=8$ VA-

$389 \mathrm{~B}, \mathrm{n}=10 \mathrm{VA}-\mathrm{W})$.

$390 \quad 3.2$ Significant neutral population structure in symbiont, but not host

391 For the coral host analysis, BayPass analyses identified 1,637 neutral and 84 high outlier

392 SNPs, and further filtering for one SNP per contig left 279 neutral loci and 66 high outlier loci

393 that were used in population differentiation analyses (Table 2). Analysis of Molecular Variance

394 (AMOVA) tests revealed no significant population structure at neutral loci (Fst $=0.002$,

395 AMOVA $p=0.269$ ); however, there was significant population structure at high outlier loci (Fst $396=0.16$, AMOVA $p=0.001$; Table 4). Pairwise differentiation between the four populations

397 reflects a similar pattern, with no significant population structure at neutral loci for most pairwise 398 comparisons (Fst ranges between -0.007 to 0.012, all $p>0.159$; Table 4) except between VA-B 399 and RI-W (Fst $=0.012, p=0.026)$. At high outlier loci, all pairwise Fst values were significant 400 (Fst ranges between 0.079 to 0.213 , all $p<0.01$; Table 4). Principal components analysis (PCA) 401 further demonstrates that all four populations overlap at neutral loci (Figure 2A) but separate 402 primarily by origin when including only putatively adaptive loci (Figure 2B).

$403 \quad$ For the symbiont analysis, BayPass analyses identified 52 neutral and 4 high outlier 404 SNPs, and further filtering for one SNP per contig left 20 neutral loci and 4 high outlier loci that 405 were used in population differentiation analyses (Table 2). In contrast to the coral host 406 population differentiation, symbiont SNPs showed significant population structure at neutral loci $407($ Fst $=0.093$, AMOVA $p=0.001$; Figure 3). At the four high outlier symbiont SNPs identified, 408 there was also significant differentiation $(\mathrm{Fst}=0.965$, AMOVA $p=0.001)$. The coral host Fst results are reflected in the STRUCTURE analysis, with a pattern of 410 admixture in all samples at neutral loci in the coral host, but two distinct clusters 
411 separating VA and RI individuals at high outlier loci (Figure S4). The optimal K value for

412 both neutral and outlier loci in the coral host was two.

\section{$413 \quad 3.3$ Genetic diversity}

414 For the coral host analysis, at neutral loci there were no clear patterns for one population

415 having higher observed (Ho) or expected (Hs) heterozygosity than another, with Ho ranging

416 between 0.217 (RI-B) to 0.283 (RI-W) and Hs ranging between 0.224 (RI-B) and 0.267 (VA-W)

417 (Table S2). At high outlier loci for the coral host, Ho and Hs was lower in VA populations (Ho:

418 VA-B $=0.121$, VA-W $=0.097$; Hs: VA-B $=0.168$, VA-W $=0.171)$, than in RI (Ho: RI-B =

$4190.191, \mathrm{RI}-\mathrm{W}=0.292$; Hs: RI-B = 0.324, RI-W =0.283; Table S2). For the neutral symbiont loci,

420 Ho and Hs were higher in the VA-B population ( 0.575 and 0.385 , respectively) than in the RI-B

421 population ( 0.47 and 0.338 , respectively). For the four high outlier symbiont SNPs, Ho and Hs

422 were both 0.0 in VA-B population, and in the RI-B population $\mathrm{Ho}=0.050$ and $\mathrm{Hs}=0.047$ (Table 423 S2).

\section{$424 \quad 3.4$ Outlier SNP identities}

425 Coral host contigs that contained more than one high outlier SNP $(n=13)$ were manually 426 inspected to look for agreement with previous studies on coral adaptation to distinct temperature 427 environments (Table S3). Some of these genes have been previously observed in coral 428 transcriptomic studies in response to thermal stress, including 40S and 60S ribosomal proteins 429 (DeSalvo et al. 2010; Portune et al. 2010), myosin heavy chain (Woo et al. 2010), and ubiquitin430 like protein FUBI (Barshis et al. 2010). Additionally, one gene (apolipoprotein B-100) was 431 previously implicated in playing a role in the coral symbiosis (Bertucci et al. 2015). Two other 432 genes were highlighted in previous transcriptomic studies in corals, including the putative 433 immune gene cyclic AMP-dependent transcription factor ATF-5 (Fuess et al. 2016) and two 
434 collagen chain proteins implicated in calcification and/or modified cell adhesion (DeSalvo et al. 435 2010).

436 There were four high outlier SNPs in symbiont reads, three of which were annotated.

437 These SNPs are on genes annotated as photosystem II (PSII) CP43 reaction center protein,

438 photosystem I (PSI) P700 chlorophyll $a$ apoprotein A2, and PSII protein D1. A full summary of 439 these contigs with multiple high outlier SNPs can be found in Table S3.

440 When analyzing the data as two populations separately for VA and RI to look for

441 consistent high outlier SNPs that could be driving differentiation between brown and white

442 morphs, 11 high outlier SNPs were identified as shared between VA and RI (Table S3), which

443 independently had 49 and 47 high outlier SNPs, respectively. These shared high outlier SNPs

444 include several previously mentioned genes (40S and 60S ribosomal proteins, cyclic AMP-

445 dependent transcription factor ATF-5, and a collagen chain protein), as well as Sequestosome-1,

446 which is implicated in autophagy and immune system process (UniProtKB entry 008623;

447 Consortium 2018).

448 3.5 High Outlier SNPs enriched for ribosome-associated GO Categories

449 Gene Ontology enrichment analyses showed that the coral host outlier SNPs detected in 450 this study were enriched for $10 \mathrm{GO}$ terms in the "molecular function" category and $7 \mathrm{GO}$ terms 451 in the "cellular components" category. The significant cellular components terms consisted of 452 several ribosome-associated terms, including large ribosomal subunit, small ribosomal subunit, 453 ribosome, and ribosomal subunit. The significant molecular function terms consisted of several 454 ribosome-associated terms, including structural constituent of ribosome and rRNA binding, as 455 well as several terms related to coral stress response, including ferric iron binding and 456 oxidoreductase (Figure S5). 


\section{4. Discussion}

459

460

461

462

463

464

465

466

467

468

469

470

471

472

473

474

475

476

477

478

479

\subsection{Opposing patterns of differentiation in Astrangia poculata hosts and symbionts}

Here, we find evidence of contrasting patterns of population structure between members of the holobiont in the temperate scleractinian coral Astrangia poculata. Between Virginia and Rhode Island, the coral host exhibited neutral panmixia, but adaptive divergence. While there was no significant population differentiation at putatively neutral loci in the host, there was evidence of neutral divergence in the algal symbiont. Astrangia poculata is a gonochoric broadcast spawning species that horizontally transmits its symbionts, a life history strategy that likely lends to the contrasting patterns of genetic differentiation in the host and symbiont observed here. Marine broadcast spawning species have extended pelagic larval durations (PLDs) of up to 244 days (Graham et al. 2008), facilitating long-range dispersal and genetic connectivity (Ayre \& Hughes 2000; Davies et al. 2017; Nishikawa et al. 2003). Combined with observations of $A$. poculata larvae swimming 5 weeks post-release in the lab (D. Wuitchik, personal communication), it is not unreasonable to expect that $A$. poculata larvae can remain in the water column for extended periods of time, facilitating larval connectivity across VA and RI.

Previous work in corals has demonstrated population connectivity across great distances. For example, high genetic connectivity was found across 4,000 km in Micronesia for two acroporid corals (Davies et al. 2015). In the Caribbean, models predict that the extended PLD (20-120 days) of Orbicella franksi enables export of larvae from the Flower Garden Banks to more distant Caribbean reefs, including Broward and Palm Beach, Florida approximately 1,500 km away (Davies et al. 2017). Additionally, across 10 Caribbean populations (bounded by Barbados in the east, Belize in the west, and the Flower Garden Banks in the north), O. faveolata 
480 exhibits strong overall connectivity $(\mathrm{Fst}=0.038)$. However, this overall connectivity was

481 complicated by regional patterns of genetic structure, including an east-west genetic barrier at

482 Mona Passage and differentiation across only $470 \mathrm{~km}$ along the Mesoamerican Barrier Reef

483 System (Rippe et al. 2017).

484

In addition to connectivity of the coral host, our results agree with previous work

485

486

487

488

489

490

491

492

493

494

495

496

497

498

499

500

501

502

demonstrating greater genetic differentiation of symbiont populations. For example, population differentiation of algal symbionts of the genus Cladocopium (C3, C40) associated with $A$.

hyacinthus and $A$. digifiera across Micronesia occurs across smaller scales compared to the coral animal (Davies et al. 2015; Davies et al. 2020). While the coral hosts exhibited gene flow across 4,000 km of the Pacific (Davies et al. 2015), the algal symbiont populations were often diverged between reefs within the same island (Davies et al. 2020). Pettay \& LaJeunesse (2013) found a similar pattern in Durusdinium glynni population structure sampled from Pocillopora (type 1) across the Eastern Tropical Pacific. In contrast to the host, which exhibited genetic connectivity over 3,400 km (Pinzon \& LaJeunesse 2011), a subtropical population of D. glynni in the Gulf of

California was differentiated from all other populations, the closest being approximately $700 \mathrm{~km}$ away (Pettay \& LaJeunesse 2013). This pattern of limited symbiont population connectivity compared to its coral host has also been shown in A. palmata hosting Symbiodinium fitti in the Caribbean (Baums et al. 2014), symbionts of the genus Cladocopium hosted by the octocoral Sinularia flexibilis on the Great Barrier Reef (Howells et al. 2009), symbiont haplotypes B1/B184 associated with corals of the genus Montastraea (Thornhill et al. 2009), and in octocorals Gorgonia ventalina (Kirk et al. 2009) and Pseudopterogorgia elisabethae (Santos et al. 2003) associated with symbionts of the genus Breviolum. Taken together, these studies on both scleractinian and gorgonian tropical corals reveal that limited connectivity of 
503 Symbiodiniaceae in comparison to the coral host is a commonly observed pattern. This suggests

504 distinct micro-evolutionary processes (e.g. lower effective dispersal in the symbiont or stronger

505 drift of symbiont genotypes within coral colonies) affect each symbiotic partner (Baums et al.

506 2014). Interestingly, our data confirm that pattern in a temperate coral species that is only

507 facultatively associated with algal symbionts, thus the factors limiting dispersal of

508 Symbiodiniaceae appear unrelated to the degree of host fidelity in the symbiosis.

509 4.2 Physical patterns of water masses could contribute to the connectivity of $\boldsymbol{A}$. poculata

510 hosts

511 Population structure of organisms whose range spans the east coast of the United States is

512 influenced by the physical properties of the ocean, where the warm waters of the Gulf Stream

513 current meet the cooler, less-saline Labrador Current to create one of the steepest gradients in

514 latitudinal temperature change in the world (Bower et al. 1985; Conover et al. 2006; Wares

515 2002). Along this latitudinal gradient, Cape Hatteras and Cape Cod are sites of particularly stark

516 environmental transitions (Wares 2002). Cape Hatteras separates warmer waters in the south (the

517 Carolinian Province) from more temperate and seasonally fluctuating waters to the north

518 (Virginian Province; Mach et al. 2011), while Cape Cod separates the Virginian Province from

519 the consistently cooler waters of the Acadian Province (Briggs 1974; Engle \& Summers 1999;

520 Mach et al. 2011). Cape Cod also represents the upper range limit of A. poculata (Peters et al.

521 1988; Thornhill et al. 2008), where it is likely restricted by the colder waters to the north

522 (Dimond et al. 2012). Both VA and RI populations considered here lie within the Virginian

523 Province and therefore between these stark environmental breaks (Figure 1). This likely

524 facilitates dispersal of $A$. poculata larvae along the coast between sites, where they might 
525 otherwise be prevented from dispersing by the Gulf Stream to the south or around Cape Cod to 526 the north.

527 These biogeographical provinces of the northwest Atlantic influence population structure 528 not just of $A$. poculata, but of a diverse collection of organisms. For example, using RAD-seq 529 Boehm et al. (2015) found two populations of the lined seahorse (Hippocampus erectus) within

530 the Virginian Province to be connected and from an ancestral gene pool that diverged from 531 populations south of Cape Hatteras in the Carolinian and Caribbean provinces. In contrast to 532 panmixia within the Virginian Province, as we also observed in the A. poculata host, Zhang et al. 533 (2014) sequenced two nuclear genes (ANT and H3) and found a break in structure in populations 534 of the amethyst gem clam (Gemma gemma; no planktonic larval phase) around New Jersey, 535 separating southern populations of Maryland, Virginia, and North Carolina from northern 536 populations of Maine, Massachusetts, and Connecticut. Such divisions in population structure 537 between what are called the Upper and Lower Virginian provinces (at $\sim 39^{\circ} \mathrm{N}$ latitude) 538 correspond with a gradient in average SST and with population structure of several other species, 539 including amphipods (Ampithoe longimana), killifish (Fundulus heteroclitus), polychaetes 540 (Marenzellaria viridis), and copepods (Eurytemora affinis) (reviewed in Wares 2002). This 541 division between Upper and Lower Virginian provinces is more consistent with what we observe 542 in B. psygmophilum population structure. In contrast to a body of literature demonstrating marine 543 species with phylogeographic structure in the northwest Atlantic, including those highlighted 544 above, Strasser \& Barber (2009) found no evidence of genetic structure in the softshell clam 545 (Mya arenaria) across the stark environmental differences between Maryland in the south and 546 Nova Scotia in the north by sequencing the mitochondrial cytochrome oxidase I gene. The 547 authors suggest that high levels of dispersal and gene flow, facilitated by a three week planktonic 
548 larval phase, likely contribute to the observed pattern (Strasser \& Barber 2009). For these studies

549 mentioned above, it is possible that differences in the genetic markers used to look for population

550 structure also influenced the ability to detect differences (D'Aloia et al. 2020). In any case, this

551 body of work highlights that oceanographic currents, planktonic larval durations and behavior,

552 life history dynamics, and the environment are all important to consider when evaluating

553 population structure in the sea.

\section{$554 \quad 4.3$ Temperature as a potential driver of adaptive population differentiation}

Although there are no severe environmental breaks between VA and RI, as both sites lie within the Virginian Province, we have previously shown that there are indeed differences in the temperature environments at our collection sites, including warmer summers in VA and colder winters in RI (Aichelman et al. 2019). These temperature differences are not restricted to the

559 time frame of this study, but are consistent over the last 40 years of SST data (Figure 1). These

560 environmental differences could drive the subtle adaptive divergence we found in the A. poculata

561 host as well as the B. psygmophilum symbiont. There is a large body of evidence demonstrating

562 that differences in temperature contribute to adaptive population differentiation in marine

563 organisms across a variety of spatial scales (reviewed in Sanford \& Kelly 2011). For example,

564 Matz et al. (2018) found population differentiation of A. millepora on the Great Barrier Reef

565 across over 1,200 km was associated with temperature. In a model simulation, this work showed

566 that even high migration rates did not interfere with patterns of local thermal adaptation, and that

567 the metapopulation could be able to adapt to predicted warming over the next 100 to 250 years

568 (Matz et al. 2018). Additionally, Haguenauer et al. (2013) found that populations of the

569 Mediterranean octocoral Corallium rubrum from distinct thermal regimes across depth $(5,20,40$

$570 \mathrm{~m}$ ) differentially induced heat shock protein 70 (HSP70) expression as a function of thermal 
571 history. Namely, shallow-water corals that historically experienced warmer temperatures more

572 strongly induced expression of HSP70 upon heat stress, and microsatellite loci showed that

573 corals from the three depths were genetically differentiated across this steep environmental

574 gradient (Haguenauer et al. 2013).

575 Gradients in environmental parameters such as temperature also play an important role in

576 local adaptation (Pettay \& LaJeunesse 2013) and genetic diversification (LaJeunesse et al. 2014)

577 of Symbiodiniaceae. Pettay \& LaJeunesse (2013) showed differentiation of the subtropical

578 population of D. glynni symbionts corresponds to environmental differentiation, including

579 seasonal variation in temperature and light. It was hypothesized that connectivity in the

580 Pocillopora coral host plus differentiation in the D. glynni symbiont resulted from larvae and

581 associated symbionts arriving from more southern reefs to the Gulf of California being rapidly

582 replaced by symbionts better adapted to the local temperate environment (Pettay \& LaJeunesse

583 2013). In contrast to A. poculata, Pocillopora maternally inherit their symbionts (vertical

584 transmission). However it is possible that, similar to Pettay \& LaJeunesse (2013), differences in

585 seasonal temperature (here between VA and RI; Aichelman et al. 2019) are driving local

586 adaptation in the $B$. psygmophilum symbionts that $A$. poculata larvae acquire upon settling in

587 their respective environments. Additionally, in the facultatively symbiotic coral Oculina

588 patagonica, Leydet \& Hellberg (2016) show that distinct symbiont communities across the

589 corals' Mediterranean range correlated with sea surface temperature rather than host genetic

590 background, supporting our hypothesis that local environment also plays an important role in

591 symbiont community structure of facultative corals.

5924.4 Outlier SNPs related to coral stress response and energetics 
594 population divergence. Namely, loci can still be under selection even in the face of extensive 595 gene flow, and therefore populations can appear homogeneous at neutral loci but still exhibit 596 local adaptation (Conover et al. 2006). Adaptive (as opposed to neutral) genetic variation affects 597 an organism's fitness (Conover et al. 2006). Here, we find evidence of $A$. poculata host 598 connectivity at neutral loci despite evidence for adaptive divergence at several high outlier sites. 599 Several of the putatively adaptive SNPs found here occur on genes that have been 600 previously associated with the coral stress response. For example, two putatively adaptive SNPs 601 were each found on genes annotated as 40S ribosomal protein S3 and 60S ribosomal protein L26. 602 Both 40S and 60S ribosomal proteins were shown to be downregulated in Acropora palmata 603 after two days of thermal stress ( $\sim 32^{\circ} \mathrm{C}$; DeSalvo et al. 2010$)$. Additionally, another four 604 putatively adaptive SNPs were found on the gene annotated as myosin heavy chain. Myosin 605 heavy chain is associated with the cytoskeleton and was previously reported to be upregulated 606 after 24 hours of thermal stress $\left(28^{\circ} \mathrm{C}\right)$ in the octocoral Scleronephthya gracillimum (Woo et al. 607 2010). Two more putatively adaptive SNPs were located on the gene annotated as ubiquitin-like 608 protein FUBI. Ubiquitin binds to damaged proteins and marks them for degradation and reuse, 609 and ubiquinated proteins are therefore thought to be a key marker for the physiological stress 610 response (Weis 2010). Barshis et al. (2010) found that ubiquitin-conjugated proteins were 611 constitutively higher in a more thermally tolerant back reef population of Porites lobata in 612 American Samoa. Lastly, although not related to coral response to thermal stress, two putatively 613 adaptive SNPs were found on a gene annotated as apolipoprotein B-100, which Bertucci et al. 614 (2015) suggest plays a role in the metabolite exchange important for the coral-algal symbiosis. It 
615 is therefore possible that adaptive differentiation between VA and RI A. poculata populations is

616 occurring at loci related to the coral stress response and/or symbiosis.

617 We found evidence of four putatively adaptive loci in B. psygmophilum, three of which

618 were annotated, including photosystem II (PSII) CP43 reaction center protein ( $p s b C$ gene; binds

619 chlorophyll and helps catalyze light-induced photochemical processes of PSII), photosystem I

620 (PSI) P700 chlorophyll $a$ apoprotein A2 ( $p s a B$ gene; reaction center chlorophyll $a$ molecule in

621 association with PSI), and PSII protein D1 ( $p s b A$ gene; core of the PSII reaction center). Species

622 of Symbiodiniaceae have been previously shown to be differentiated by mutations on genes

623 related to photosystem machinery. Wham et al. (2017) found that Durusdinium glynnii was

624 distinguished from other symbionts within the genus Durusdinium as well as from symbionts of

625 other genera by a non-synonymous mutation that effected a change on the D1 protein of

626 photosystem II ( $p s b A$ gene), a highly conserved region in dinoflagellates (Iida et al. 2008). This

627 could indicate that differences in temperature and/or light environment between VA and RI are

628 driving adaptive differentiation of B. psygmophilum populations at loci related to photosynthetic

629 machinery. Future work should aim to further characterize the differentiation of $B$.

630 psygmophilum across the latitudinal range of $A$. poculata, for example by sequencing other

631 pertinent regions of the genome (i.e. chloroplast-encoded 23S rDNA or internal transcribed

632 spacers) or considering cell size differences (e.g. LaJeunesse et al. 2012; LaJeunesse et al. 2014).

633 Additionally, as there appears to be some differentiation between white and brown corals

634 based on the PCA analysis (Figure 2B) and within population pairwise Fst calculations, it is

635 tempting to speculate that there are factors driving genetic divergence between symbiotic states.

636 By considering each population separately and looking for consistent outlier SNP identities, we

637 do not find compelling evidence to support this hypothesis as only 11 out of 49 (for VA) and 47 
638 (for RI) outlier SNPs were shared between the two groups. Thus, we find it less parsimonious

639 that each population has uniquely evolved genetic differentiation between symbiotic states, as we

640 imagine a high degree of conservation/shared evolutionary history in this trait. However, there is

641 one interesting high outlier SNP in both VA and RI, annotated as Sequestosome-1, that could

642 potentially be related to differentiation between symbiotic state. Sequestosome-1 (UniProtKB

643 entry 008623; Consortium 2018) is involved in autophagy, and may regulate the activation of

644 NF-kB1 (a conserved immune regulatory protein) by TNF-alpha. Previous work in a sea

645 anemone model by Mansfield et al. (2017) suggested that NF-kB levels were related to

646 symbiotic state, and Symbiodiniaceae suppressed NF-кB to establish symbiosis with Exaiptasia

647 pallida. While it is possible that our results could signify a host-specific genotypic difference

648 that is associated with being symbiotic or aposymbiotic, it is far from definitive. The

649 environmental and/or genetic factors determining which A. poculata individuals are symbiotic

650 and which are aposymbiotic therefore remains elusive, and certainly warrants further

651 exploration.

652 For both the coral host and symbiont outlier loci, it is important to acknowledge the

653 possibility that some of the SNPs we discuss above are false positives, and not true signatures of

654 local adaptation. Additionally, it will be important to conduct deeper sequencing and analyze

655 additional loci across multiple populations to have more confidence in the outlier loci driving

656 differentiation across the range of $A$. poculata.

657

\section{5. Conclusions}

659 Here, we found contrasting levels of genetic connectivity in the different partners of the 660 Astrangia poculata holobiont, with neutral gene flow and adaptive divergence in the coral host 
661 versus neutral and adaptive divergence in the algal symbiont. This highlights how the interacting

662 forces of oceanography, environmentally driven selection, local adaptation, and reproductive

663 biology can manifest in differential connectivity of a marine holobiont system. Previously, we

664 found physiological differentiation in coral host metrics (i.e. respiration rate and thermal

665 optima), but not in symbiont physiology (i.e. photosynthesis rate and photochemical efficiency)

666 (Aichelman et al. 2019). Interestingly, here we find the opposite, namely a stronger signal of

667 divergence in the algal symbiont. It is possible that our previous hypothesis regarding symbiont

668 acclimation to aquarium light conditions accounts for this discrepancy, but future work should

669 aim to disentangle the possibility for local adaptation acting at different levels of the $A$. poculata

670 holobiont. Although A. poculata inhabits hard bottom communities throughout the mid-Atlantic,

671 much remains to be learned about the physiological and molecular mechanisms that facilitate its

672 persistence in such extreme temperature ranges, particularly outside the more northern range

673 focus of this study. Future work should explore extended sampling, and include deeper

674 sequencing to improve the search for potentially selected alleles, across the strong potential

675 biogeographic break of the Gulf Stream at Cape Hatteras as well as increasing the spatial

676 resolution to characterize the scale of connectivity in the weakly dispersing symbionts. Such

677 work will help elucidate the potential role of temperature in driving local adaptation of $A$.

678 poculata and B. psygmophilum, and could provide insights into how the population dynamics of

679 this holobiont could change as temperatures continue to warm.

680

681 6. Acknowledgements

682 We extend appreciation to K. Sharp, R. Rotjan, S. Grace and the annual Astrangia Workshop

683 hosted by Roger Williams University for fostering creative conversations and collaborations 
684 leading to this work. We thank Sandrine Boissel and Courtney Klepac for assistance with field

685 collections and lab work and Dr. Hanny Rivera for assistance with STRUCTURE and other

686 beneficial discussions regarding data analysis. Also, thanks to Kristina Bounds and Matt

687 Bengtson for assistance with aquaria maintenance. This research was supported by the Research

688 Computing clusters at Old Dominion University.

689

690

691

692

693

694

695

696

697

698

699

700

701

702

703

704

705

706

707

708

709

710

711

712

713

714

715

716

717

718

719

720

\section{References}

Aichelman HE, Zimmerman RC, and Barshis DJ. 2019. Adaptive signatures in thermal performance of the temperate coral Astrangia poculata (Ellis \& Solander, 1786). Journal of Experimental Biology:jeb. 189225.

Angilletta MJ. 2009. Thermal adaptation: a theoretical and empirical synthesis: Oxford University Press.

Aurelle D, Ledoux J-B, Rocher C, Borsa P, Chenuil A, and Féral J-P. 2011. Phylogeography of the red coral (Corallium rubrum): inferences on the evolutionary history of a temperate gorgonian. Genetica 139:855.

Ayre DJ, and Hughes TP. 2000. Genotypic diversity and gene flow in brooding and spawning corals along the Great Barrier Reef, Australia. Evolution 54:1590-1605.

Banzon V, Smith TM, Steele M, Huang B, and Zhang H-M. 2020. Improved Estimation of Proxy Sea Surface Temperature in the Arctic. Journal of Atmospheric and Oceanic Technology 37:341-349.

Barshis DJ, Birkeland C, Toonen RJ, Gates RD, and Stillman JH. 2018. High-frequency temperature variability mirrors fixed differences in thermal limits of the massive coral Porites lobata (Dana, 1846). Journal of Experimental Biology:jeb. 188581.

Barshis DJ, Ladner JT, Oliver TA, Seneca FO, Traylor-Knowles N, and Palumbi SR. 2013. Genomic basis for coral resilience to climate change. Proceedings of the National Academy of Sciences 110:1387-1392.

Barshis DJ, Stillman JH, Gates RD, Toonen RJ, Smith LW, and Birkeland C. 2010. Protein expression and genetic structure of the coral Porites lobata in an environmentally extreme Samoan back reef: does host genotype limit phenotypic plasticity? Molecular Ecology 19:1705-1720.

Baums IB, Devlin - Durante MK, and LaJeunesse TC. 2014. New insights into the dynamics between reef corals and their associated dinoflagellate endosymbionts from population genetic studies. Molecular Ecology 23:4203-4215.

Bay RA, and Palumbi SR. 2014. Multilocus adaptation associated with heat resistance in reefbuilding corals. Current Biology 24:2952-2956. 
721 Bertucci A, Foret S, Ball E, and Miller DJ. 2015. Transcriptomic differences between day and

722

723

724

725

726

727

728

729

730

731

732

733

734

735

736

737

738

739

740

741

742

743

744

745

746

747

748

749

750

751

752

753

754

755

756

757

758

759

760

761

762

763

764 night in Acropora millepora provide new insights into metabolite exchange and light - enhanced calcification in corals. Molecular Ecology 24:4489-4504.

Boehm J, Waldman J, Robinson JD, and Hickerson MJ. 2015. Population genomics reveals seahorses (Hippocampus erectus) of the western mid-Atlantic coast to be residents rather than vagrants. PloS One 10:e116219.

Boschma H. 1925. The nature of the association between anthozoa and zooxanthellae. Proceedings of the National Academy of Sciences 11:65-67.

Bower AS, Rossby HT, and Lillibridge JL. 1985. The Gulf Stream-barrier or blender? Journal of Physical Oceanography 15:24-32.

Bradbury IR, Hubert S, Higgins B, Borza T, Bowman S, Paterson IG, Snelgrove PV, Morris CJ, Gregory RS, and Hardie DC. 2010. Parallel adaptive evolution of Atlantic cod on both sides of the Atlantic Ocean in response to temperature. Proceedings of the Royal Society B: Biological Sciences 277:3725-3734.

Bradbury IR, Laurel B, Snelgrove PV, Bentzen P, and Campana SE. 2008. Global patterns in marine dispersal estimates: the influence of geography, taxonomic category and life history. Proceedings of the Royal Society B: Biological Sciences 275:1803-1809.

Briggs JC. 1974. Marine zoogeography.

Coelho MA, and Lasker HR. 2016. Larval dispersal and population connectivity in Anthozoans. The Cnidaria, Past, Present and Future: Springer, 291-315.

Conover D, Clarke L, Munch S, and Wagner G. 2006. Spatial and temporal scales of adaptive divergence in marine fishes and the implications for conservation. Journal of Fish Biology 69:21-47.

Consortium U. 2018. UniProt: a worldwide hub of protein knowledge. Nucleic Acids Research 47:D506-D515.

Coordinators NR. 2018. Database resources of the national center for biotechnology information. Nucleic Acids Research 46:D8.

Costantini F, Fauvelot C, and Abbiati M. 2007. Fine-scale genetic structuring in Corallium rubrum: evidence of inbreeding and limited effective larval dispersal. Marine Ecology Progress Series 340:109-119.

Crisci C, Ledoux J-B, Mokhtar-Jamaï K, Bally M, Bensoussan N, Aurelle D, Cebrian E, Coma R, Féral J-P, and La Riviere M. 2017. Regional and local environmental conditions do not shape the response to warming of a marine habitat-forming species. Scientific Reports 7:1-13.

D’ Aloia CC, Andrés JA, Bogdanowicz SM, McCune AR, Harrison RG, and Buston PM. 2020. Unraveling hierarchical genetic structure in a marine metapopulation: A comparison of three high - throughput genotyping approaches. Molecular Ecology.

Dao HT, Smith-Keune C, Wolanski E, Jones CM, and Jerry DR. 2015. Oceanographic currents and local ecological knowledge indicate, and genetics does not refute, a contemporary pattern of larval dispersal for the ornate spiny lobster, Panulirus ornatus in the southeast Asian archipelago. PloS One 10:e0124568.

Davies S, Treml E, Kenkel C, and Matz MV. 2015. Exploring the role of Micronesian islands in the maintenance of coral genetic diversity in the Pacific Ocean. Molecular Ecology 24:70-82. 
765 Davies SW, Marchetti A, Ries JB, and Castillo KD. 2016. Thermal and pCO2 stress elicit

766

767

768

769

770

771

772

773

774

775

776

777

778

779

780

781

782

783

784

785

786

787

788

789

790

791

792

793

794

795

796

797

798

799

800

801

802

803

804

805

806

807

808

809 divergent transcriptomic responses in a resilient coral. Frontiers in Marine Science 3:112.

Davies SW, Moreland K, Wham D, Kanke M, and Matz M. 2020. Cladocopium community divergence in two Acropora coral hosts across multiple spatial scales. bioRxiv:575183.

Davies SW, Strader ME, Kool JT, Kenkel CD, and Matz MV. 2017. Modeled differences of coral life-history traits influence the refugium potential of a remote Caribbean reef. Coral Reefs 36:913-925.

De Wit P, Pespeni MH, Ladner JT, Barshis DJ, Seneca F, Jaris H, Therkildsen NO, Morikawa M, and Palumbi SR. 2012. The simple fool's guide to population genomics via RNA - Seq: an introduction to high - throughput sequencing data analysis. Molecular Ecology Resources 12:1058-1067.

DeSalvo MK, Sunagawa S, Voolstra CR, and Medina M. 2010. Transcriptomic responses to heat stress and bleaching in the elkhorn coral Acropora palmata. Marine Ecology Progress Series 402:97-113.

Dimond JL, Kerwin AH, Rotjan R, Sharp K, Stewart FJ, and Thornhill DJ. 2012. A simple temperature-based model predicts the upper latitudinal limit of the temperate coral Astrangia poculata. Coral Reefs 32:401-409. 10.1007/s00338-012-0983-z

Dixon GB, Davies SW, Aglyamova GV, Meyer E, Bay LK, and Matz MV. 2015. Genomic determinants of coral heat tolerance across latitudes. Science 348:1460-1462.

Engle V, and Summers J. 1999. Latitudinal gradients in benthic community composition in Western Atlantic estuaries. Journal of Biogeography 26:1007-1023.

Evanno G, Regnaut S, and Goudet J. 2005. Detecting the number of clusters of individuals using the software STRUCTURE: a simulation study. Molecular Ecology 14:2611-2620.

Falush D, Stephens M, and Pritchard JK. 2007. Inference of population structure using multilocus genotype data: dominant markers and null alleles. Molecular Ecology Notes 7:574-578.

Fuess LE, Weil E, and Mydlarz LD. 2016. Associations between transcriptional changes and protein phenotypes provide insights into immune regulation in corals. Developmental \& Comparative Immunology 62:17-28.

Garrison E, and Marth G. 2012. Haplotype-based variant detection from short-read sequencing. arXiv preprint arXiv:12073907.

Gautier M. 2015. Genome-wide scan for adaptive divergence and association with population-specific covariates. Genetics 201:1555-1579.

Grabherr MG, Haas BJ, Yassour M, Levin JZ, Thompson DA, Amit I, Adiconis X, Fan L, Raychowdhury R, and Zeng Q. 2011. Full-length transcriptome assembly from RNASeq data without a reference genome. Nature Biotechnology 29:644.

Graham E, Baird A, and Connolly S. 2008. Survival dynamics of scleractinian coral larvae and implications for dispersal. Coral Reefs 27:529-539.

Günther T, and Coop G. 2013. Robust identification of local adaptation from allele frequencies. Genetics 195:205-220.

Haguenauer A, Zuberer F, Ledoux J-B, and Aurelle D. 2013. Adaptive abilities of the Mediterranean red coral Corallium rubrum in a heterogeneous and changing environment: from population to functional genetics. Journal of Experimental Marine Biology and Ecology 449:349-357. 
810 Hamming RW. 1950. Error detecting and error correcting codes. The Bell System Technical

811

812

813

814

815

816

817

818

819

820

821

822

823

824

825

826

827

828

829

830

831

832

833

834

835

836

837

838

839

840

841

842

843

844

845

846

847

848

849

850

851

852

853

854 Journal 29:147-160.

Howells E, Van Oppen M, and Willis B. 2009. High genetic differentiation and cross-shelf patterns of genetic diversity among Great Barrier Reef populations of Symbiodinium. Coral Reefs 28:215-225.

Iida S, Kobiyama A, Ogata T, and Murakami A. 2008. The D1 and D2 proteins of dinoflagellates: unusually accumulated mutations which influence on PSII photoreaction. Photosynthesis Research 98:415-425.

Jacques TGM, N.; Pilson, M.E.Q. 1983. Experimental ecology of the temperate scleractinian coral Astrangia danae II. Effect of temperature, light intensity and symbiosis with zooxanthellae on metabolic rate and calcification. Marine Biology 76:135-148.

Kamvar ZN, Brooks JC, and Grünwald NJ. 2015. Novel R tools for analysis of genome-wide population genetic data with emphasis on clonality. Frontiers in Genetics 6:208.

Kamvar ZN, Tabima JF, and Grünwald NJ. 2014. Poppr: an R package for genetic analysis of populations with clonal, partially clonal, and/or sexual reproduction. PeerJ 2:e281.

Kenkel C, Goodbody - Gringley G, Caillaud D, Davies S, Bartels E, and Matz M. 2013. Evidence for a host role in thermotolerance divergence between populations of the mustard hill coral (Porites astreoides) from different reef environments. Molecular Ecology 22:4335-4348.

Kenkel CD, and Matz MV. 2016. Gene expression plasticity as a mechanism of coral adaptation to a variable environment. Nature Ecology \& Evolution 1:0014.

Kirk NL, Andras JP, Harvell CD, Santos SR, and Coffroth MA. 2009. Population structure of Symbiodinium sp. associated with the common sea fan, Gorgonia ventalina, in the Florida Keys across distance, depth, and time. Marine Biology 156:1609-1623.

Knowlton N, and Rohwer F. 2003. Multispecies microbial mutualisms on coral reefs: the host as a habitat. American Naturalist 162:S51-S62.

Kopelman NM, Mayzel J, Jakobsson M, Rosenberg NA, and Mayrose I. 2015. Clumpak: a program for identifying clustering modes and packaging population structure inferences across K. Molecular Ecology Resources 15:1179-1191.

Ladner JT, and Palumbi SR. 2012. Extensive sympatry, cryptic diversity and introgression throughout the geographic distribution of two coral species complexes. Molecular Ecology 21:2224-2238.

LaJeunesse TC, Parkinson JE, Gabrielson PW, Jeong HJ, Reimer JD, Voolstra CR, and Santos SR. 2018. Systematic revision of Symbiodiniaceae highlights the antiquity and diversity of coral endosymbionts. Current Biology 28:2570-2580. e2576.

LaJeunesse TC, Parkinson JE, and Reimer JD. 2012. A genetics - based description of Symbiodinium minutum sp. nov. and S. psygmophilum sp. nov.(Dinophyceae), two dinoflagellates symbiotic with cnidaria. Journal of Phycology 48:1380-1391.

LaJeunesse TC, Wham DC, Pettay DT, Parkinson JE, Keshavmurthy S, and Chen CA. 2014. Ecologically differentiated stress-tolerant endosymbionts in the dinoflagellate genus Symbiodinium (Dinophyceae) Clade D are different species. Phycologia 53:305-319.

Langmead B, and Salzberg SL. 2012. Fast gapped-read alignment with Bowtie 2. Nature Methods 9:357.

Ledoux JB, Aurelle D, Bensoussan N, Marschal C, Féral JP, and Garrabou J. 2015. Potential for adaptive evolution at species range margins: contrasting interactions between red 
855

856

857

858

859

860

861

862

863

864

865

866

867

868

869

870

871

872

873

874

875

876

877

878

879

880

881

882

883

884

885

886

887

888

889

890

891

892

893

894

895

896

897

coral populations and their environment in a changing ocean. Ecology and Evolution 5:1178-1192.

Ledoux JB, Garrabou J, Bianchimani O, Drap P, Féral JP, and Aurelle D. 2010. Fine - scale genetic structure and inferences on population biology in the threatened Mediterranean red coral, Corallium rubrum. Molecular Ecology 19:4204-4216.

Leydet KP, and Hellberg ME. 2016. Discordant coral-symbiont structuring: factors shaping geographical variation of Symbiodinium communities in a facultative zooxanthellate coral genus, Oculina. Coral Reefs 35:583-595.

Li YL, and Liu JX. 2018. StructureSelector: A web - based software to select and visualize the optimal number of clusters using multiple methods. Molecular Ecology Resources 18:176-177.

Limborg MT, Helyar SJ, De Bruyn M, Taylor MI, Nielsen EE, Ogden R, Carvalho GR, Consortium F, and Bekkevold D. 2012. Environmental selection on transcriptome - derived SNPs in a high gene flow marine fish, the Atlantic herring (Clupea harengus). Molecular Ecology 21:3686-3703.

Mach ME, Sbrocco EJ, Hice LA, Duffy TA, Conover DO, and Barber PH. 2011. Regional differentiation and post-glacial expansion of the Atlantic silverside, Menidia menidia, an annual fish with high dispersal potential. Marine Biology 158:515-530.

Mansfield KM, Carter NM, Nguyen L, Cleves PA, Alshanbayeva A, Williams LM, Crowder C, Penvose AR, Finnerty JR, and Weis VM. 2017. Transcription factor NF- $\mathrm{KB}$ is modulated by symbiotic status in a sea anemone model of cnidarian bleaching. Scientific Reports 7:1-14.

Matz MV, Treml EA, Aglyamova GV, and Bay LK. 2018. Potential and limits for rapid genetic adaptation to warming in a Great Barrier Reef coral. PLoS Genetics 14:e1007220.

Meirmans PG, and Van Tienderen PH. 2004. GENOTYPE and GENODIVE: two programs for the analysis of genetic diversity of asexual organisms. Molecular Ecology Notes 4:792794.

Nishikawa A, Katoh M, and Sakai K. 2003. Larval settlement rates and gene flow of broadcastspawning (Acropora tenuis) and planula-brooding (Stylophora pistillata) corals. Marine Ecology Progress Series 256:87-97.

Oksanen J, Blanchet F, Kindt R, Legendre P, Minchin P, O'hara R, Simpson G, Solymos P, Stevens M, and Wagner H. 2011. Vegan: community ecology package: ordination, diversity and dissimilarities. $R$ package version 2:4-3.

Peters EC, Cairns SD, Pilson ME, Wells JW, Jaap WC, Lang JC, Vasleski C, and St Pierre Gollahon L. 1988. Nomenclature and biology of Astrangia poculata $(=A$. danae $=A$. astreiformis)(Cnidaria: Anthozoa). Proceedings of the Biological Society of Washington 101:234-250.

Pettay DT, and LaJeunesse TC. 2013. Long-range dispersal and high-latitude environments influence the population structure of a "stress-tolerant" dinoflagellate endosymbiont. PloS One 8:e79208.

Pinzon JH, and LaJeunesse TC. 2011. Species delimitation of common reef corals in the genus Pocillopora using nucleotide sequence phylogenies, population genetics and symbiosis ecology. Molecular Ecology 20:311-325. 
898 Portune KJ, Voolstra CR, Medina M, and Szmant AM. 2010. Development and heat stress-

899

900

901

902

903

904

905

906

907

908

909

910

911

912

913

914

915

916

917

918

919

920

921

922

923

924

925

926

927

928

929

930

931

932

933

934

935

936

937

938

939

940

941

942

943 induced transcriptomic changes during embryogenesis of the scleractinian coral Acropora palmata. Marine Genomics 3:51-62.

Prevosti A, Ocana J, and Alonso G. 1975. Distances between populations of Drosophila subobscura, based on chromosome arrangement frequencies. Theoretical and Applied Genetics 45:231-241.

Puritz JB, Hollenbeck CM, and Gold JR. 2014a. dDocent: a RADseq, variant-calling pipeline designed for population genomics of non-model organisms. PeerJ 2:e431.

Puritz JB, Matz MV, Toonen RJ, Weber JN, Bolnick DI, and Bird CE. 2014b. Demystifying the RAD fad. Molecular Ecology 23:5937-5942.

R Core Team. 2017. R: A language and environment for statistical computing. 3.4.0 ed. Vienna, Austria.

Rippe JP, Matz MV, Green EA, Medina M, Khawaja NZ, Pongwarin T, Pinzón C JH, Castillo KD, and Davies SW. 2017. Population structure and connectivity of the mountainous star coral, Orbicella faveolata, throughout the wider Caribbean region. Ecology and Evolution 7:9234-9246.

Rohwer F, Seguritan V, Azam F, and Knowlton N. 2002. Diversity and distribution of coralassociated bacteria. Marine Ecology Progress Series 243:1-10.

Sanford E, and Kelly MW. 2011. Local adaptation in marine invertebrates. Annual Review of Marine Science 3:509-535.

Santos S, Gutierrez-Rodriguez C, Lasker H, and Coffroth M. 2003. Symbiodinium sp. associations in the gorgonian Pseudopterogorgia elisabethae in the Bahamas: high levels of genetic variability and population structure in symbiotic dinoflagellates. Marine Biology 143:111-120.

Selkoe K, and Toonen RJ. 2011. Marine connectivity: a new look at pelagic larval duration and genetic metrics of dispersal. Marine Ecology Progress Series 436:291-305.

Selkoe KA, Henzler CM, and Gaines SD. 2008. Seascape genetics and the spatial ecology of marine populations. Fish and Fisheries 9:363-377.

Strasser CA, and Barber PH. 2009. Limited genetic variation and structure in softshell clams (Mya arenaria) across their native and introduced range. Conservation Genetics 10:803.

Szmant-Froelich AY, Paul; Pilson, Michael E.Q. 1980. Gametogenesis and Early Development of the Temperate Coral Astrangia danae (Anthozoa: Scleractinia). Biological Bulletin 158:257-269.

Thornhill DJ, Kemp DW, Bruns BU, Fitt WK, and Schmidt GW. 2008. Correspondence between cold tolerance and temperate biogeography in a Western Atlantic Symbiodinium (Dinophyta) Lineage(1). Journal of Phycology 44:1126-1135.

Thornhill DJ, Xiang Y, Fitt WK, and Santos SR. 2009. Reef endemism, host specificity and temporal stability in populations of symbiotic dinoflagellates from two ecologically dominant Caribbean corals. PloS One 4:e6262.

Wang C, Kao W-H, and Hsiao CK. 2015. Using Hamming distance as information for SNP-sets clustering and testing in disease association studies. PloS One 10:e135918.

Wares J. 2002. Community genetics in the Northwestern Atlantic intertidal. Molecular Ecology 11:1131-1144.

Weis VM. 2010. The susceptibility and resilience of corals to thermal stress: adaptation, acclimatization or both? Molecular Ecology 19:1515-1517.

Peer) reviewing PDF | (2020:04:47962:1:1:NEW 28 Aug 2020) 
944 Wessel P, and Smith WH. 1996. A global, self - consistent, hierarchical, high - resolution

945

946

947

948

949

950

951

952

953

954

955

956 shoreline database. Journal of Geophysical Research: Solid Earth 101:8741-8743.

Wham DC, Ning G, and LaJeunesse TC. 2017. Symbiodinium glynnii sp. nov., a species of stresstolerant symbiotic dinoflagellates from pocilloporid and montiporid corals in the Pacific Ocean. Phycologia 56:396-409.

Woo S, Jeon H-y, Lee J, Song J-I, Park H-S, and Yum S. 2010. Isolation of hyperthermal stress responsive genes in soft coral (Scleronephthya gracillimum). Molecular \& Cellular Toxicology 6:384-390.

Zhang H, Geller JB, and Vrijenhoek RC. 2014. Genetic diversity in native and introduced populations of the amethyst gem clam Gemma gemma (Totten, 1834) from the US east and west coasts. Biological Invasions 16:2725-2735. 
Figure 1

Maximum sea surface temperatures averaged across 1982 to 2018 for part of the range of Astrangia poculata, including the populations sampled in this study.

Virginia $=$ VA and Rhode Island $=$ RI. The over-water distance between the two collection

sites is approximately $630 \mathrm{~km}$. Biogeographic province designations are from Briggs (1974) and Engle and Summers (2001). 


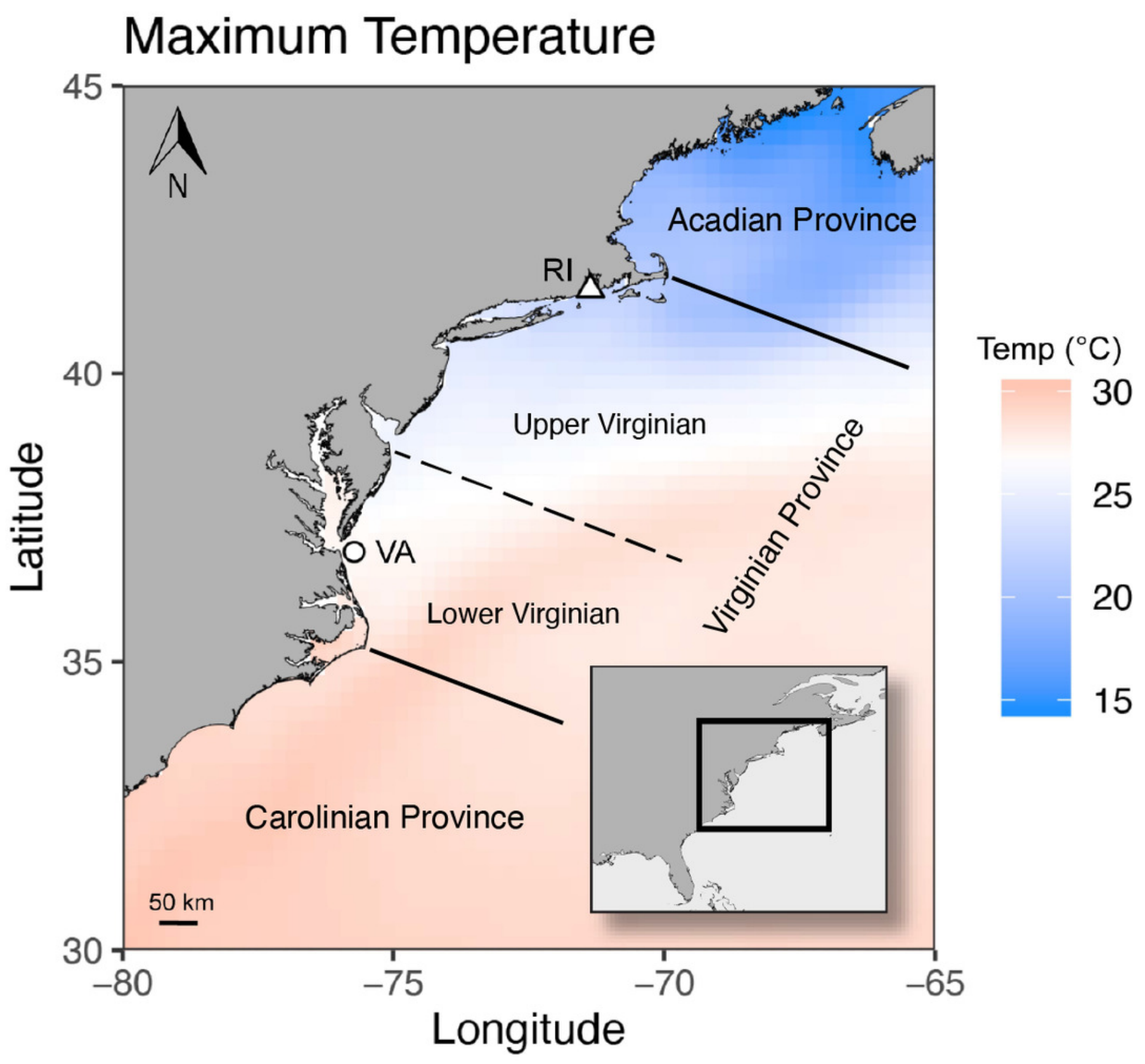


Figure 2

Principal Component Analysis (PCA) of neutral $(A, n=279)$ and high outlier $(B, n=66)$ Astrangia poculata SNPs of the four populations.

Colors represent the four populations: dark orange $=$ VA-B (brown/symbiotic Virginia), light orange $=$ VA-W (white/aposymbiotic Virginia), dark blue $=$ RI-B (brown/symbiotic Rhode Island), and light blue $=\mathrm{RI}-\mathrm{W}$ (white/aposymbiotic Rhode Island). Fst values and associated p-values are from Analysis of Molecular Variance (AMOVA) tests implemented in Genodive. The $x$ - and $y$-axes indicate the percent of the variance explained by the first and second principal component, respectively. Insets indicate the eigenvalues of the first six principal components.

\section{A. Neutral Loci}

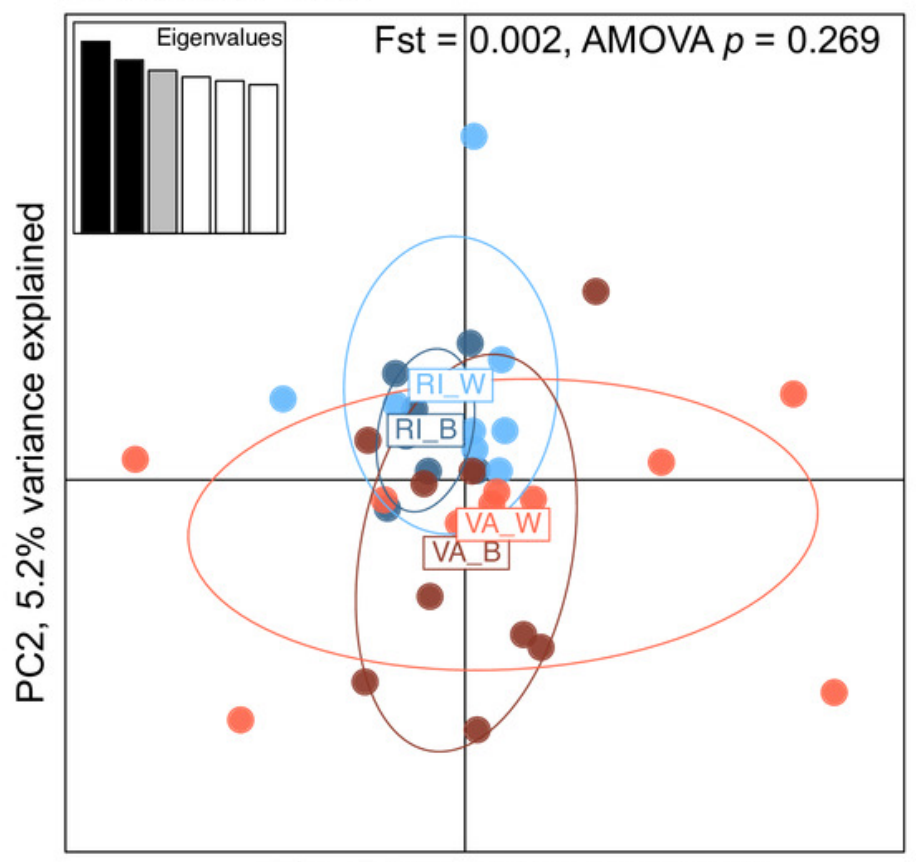

PC1, 5.8\% variance explained
B. High Outlier Loci

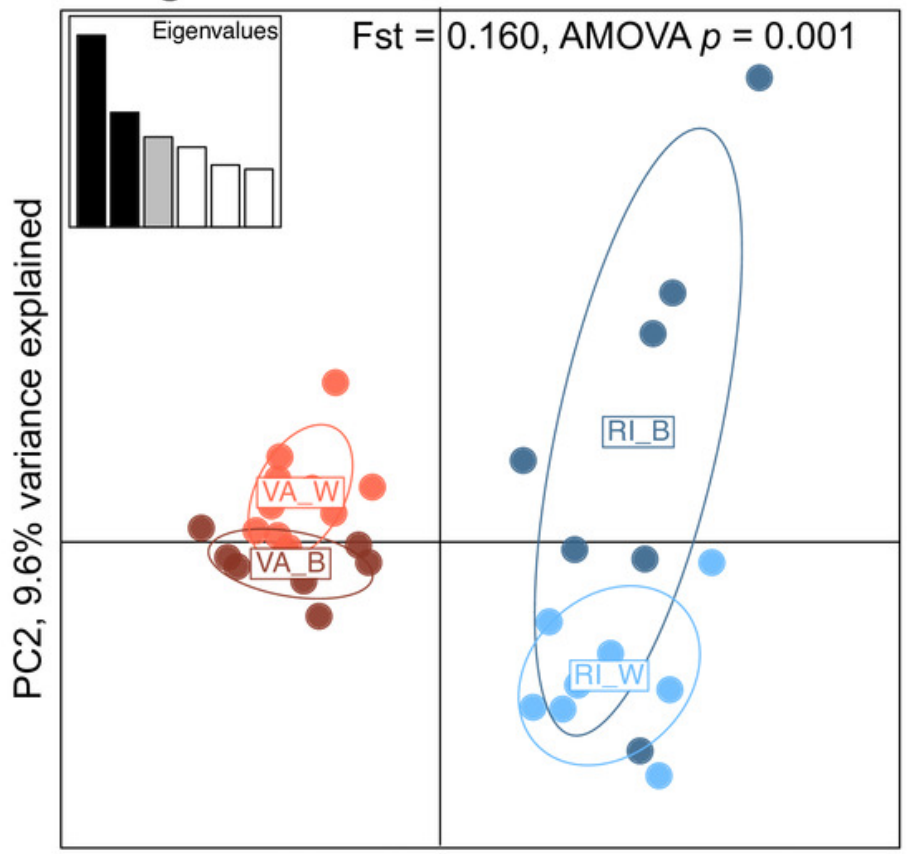

PC1, 16.1\% variance explained 
Figure 3

Principal Component Analysis (PCA) of neutral Breviolum psygomphilum SNPs $(n=20)$.

Colors represent the two populations: dark orange $=$ VA-B (brown/symbiotic Virginia) and dark blue $=$ RI-B (brown/symbiotic Rhode Island). Fst, associated $p$-values, and labeling are as in Figure 2. 
Neutral Loci

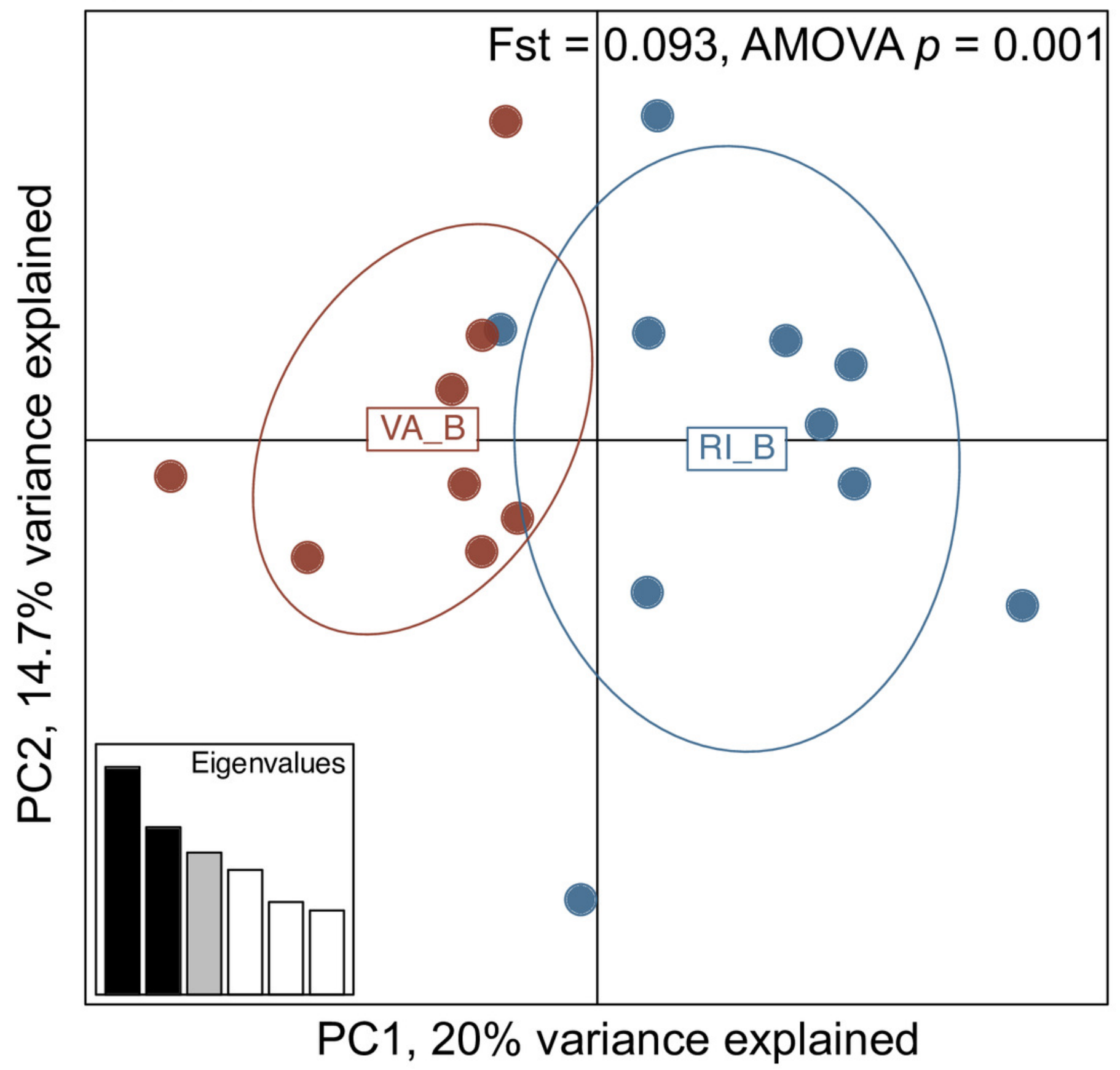




\section{Table $\mathbf{1}$ (on next page)}

Summary statistics for the Astrangia poculata and Breviolum psygmophilum combined reference assembly constructed using Trinity. 
1

\begin{tabular}{|ll}
\hline Total number of sequences & 15,079 \\
\hline Average sequence length & $876 \mathrm{bp}$ \\
\hline N50 & 881 \\
\hline Median sequence length & $578 \mathrm{bp}$ \\
\hline Percent annotated & $91.7 \%$
\end{tabular}

2 


\section{Table 2 (on next page)}

Summary of number of SNPs.

Summary of the number of SNPs after original filtering using vcftools (A) and after filtering to include only one SNP per contig as in the dDocent pipeline (B). Filtering for 1 SNP per contig was done after original filtering using vcftools and separating neutral and high outlier loci. Number of SNPs are included for the host (VA-B, VA-W, RI-B, RI-W) and symbiont (VA-B and RI-B) analyses discussed here. 
1

\begin{tabular}{lll}
\hline Analysis Step & Host & Symbiont \\
\hline (A) Filtered $\boldsymbol{v c f}$ File & & \\
\hline Total number of SNPs & 1808 & 59 \\
\hline High Outlier SNPs & 84 & 4 \\
\hline Neutral SNPs & 1637 & 52 \\
\hline
\end{tabular}

\section{(B) Filtered 1 SNP per Contig}

File

High Outlier SNPs

Neutral SNPs

$\begin{array}{ll}66 & 4 \\ 279 & 20\end{array}$

2

3

4 


\section{Table 3(on next page)}

Summary of sequencing and mapping results.

Each category contains the range on the first line and the average $+/$ - standard error below. 
1

\begin{tabular}{ll}
\hline Filter Type & Number of Reads \\
\hline After Merging Files by Genotype & $9,340,966-167,484,549$ \\
& $(51,082,950.3 \pm 4,634,637.5)$ \\
\hline Singly Aligned Mapped & $4,720,063-85,431,605$ \\
& $(25,860,167.1 \pm 2,361,454.9)$ \\
\hline \% Singly Aligned Mapped & $45.96-54.1 \%$ \\
& $(50.6 \pm 0.26 \%)$ \\
\hline
\end{tabular}

2 


\section{Table 4 (on next page)}

Pairwise differentiation (Fst) results from Genodive for the Astrangia poculata host.

Virginia $=$ VA and Rhode Island $=\mathrm{RI}, \mathrm{B}=$ symbiotic host, $\mathrm{W}=$ aposymbiotic host. The first number reported is the Fst value and the number following in parentheses is the $p$-value (significance was tested using 999 permutations in Genodive). Significant pairwise differentiation results are bolded. In each box, the results on the top are for putatively neutral loci, and the results underneath are for high outlier loci. 
1

\begin{tabular}{|c|c|c|c|c|}
\hline & VA-B & VA-W & RI-B & RI-W \\
\hline VA-B & -- & -- & -- & -- \\
\hline VA-W & $\begin{array}{l}-0.007(0.842) \\
\mathbf{0 . 0 9 4}(\mathbf{0 . 0 0 1})\end{array}$ & -- & -- & -- \\
\hline RI-B & $\begin{array}{l}0.008(0.159) \\
\mathbf{0 . 2 1 3}(\mathbf{0 . 0 0 1})\end{array}$ & $\begin{array}{l}-0.003(0.649) \\
\mathbf{0 . 1 8 9}(\mathbf{0 . 0 0 1 )}\end{array}$ & -- & -- \\
\hline RI-W & $\begin{array}{l}0.012(0.026) \\
0.196(0.001)\end{array}$ & $\begin{array}{l}0.002(0.377) \\
0.181(\mathbf{0 . 0 0 1})\end{array}$ & $\begin{array}{l}0.003(0.325) \\
\mathbf{0 . 0 7 9}(\mathbf{0 . 0 0 2})\end{array}$ & -- \\
\hline
\end{tabular}

2

3

4 